\title{
Seguridad digital, ¿cómo se perciben los docentes en formación?
}

\section{Digital security, how do teachers in training perceived themselves?}

\author{
Mario Grande-de-Prado. \\ Universidad de León (ULE). España. \\ mgrap@unileon.es \\ Ruth Cañón-Rodríguez. \\ Universidad de León (ULE). España. \\ rcanr@unileon.es \\ Sheila García-Martín. \\ Universidad de León (ULE). España. \\ sgarcm@unileon.es
}

\section{RESUMEN.}

El objetivo de esta investigación es conocer y analizar la autopercepción que el alumnado que empieza el Grado de Maestro de Educación Primaria tiene sobre su capacidad para preservar su privacidad y seguridad en el entorno digital. Esta capacidad se ha convertido en nuestra sociedad en algo fundamental y constituye un reto educativo relevante. Este estudio ha empleado una metodología descriptiva- interpretativa y ex post facto utilizando para la recogida de datos un cuestionario dirigido al alumnado del primer curso de Grado de Maestros de Educación Primaria de la Universidad de León, durante cuatro años. En base a los resultados obtenidos podemos afirmar, en términos generales, que los estudiantes del primer curso del Grado de Educación Primaria de la Universidad de León se valoran como competentes, aunque no debemos olvidar que estos resultados solo muestran la autopercepción de éstos. Resultan destacables las diferencias encontradas en base al sexo.

\section{PALABRAS CLAVE.}

Competencia digital, TIC, educación superior, formación del profesorado.

\section{ABSTRACT.}

The aim of this research is to know and analyze the self-perception that the students who start the Primary Teacher Education Degree have about their ability to preserve their privacy and security in the digital environment. This capacity has become in our society something fundamental and constitutes a relevant educational challenge. This study has used a descriptive-interpretative methodology and ex post facto using a questionnaire for the collection of data of the students of the first year of the Primary Teacher Education Degree of the University of León, for four years. After collecting data of more than three hundred students over several years, we can state in general terms that the research data indicate that the students in the sample are considered competent, although we should not forget that these results only show the students' self-perception. Differences found based on sex are noteworthy.

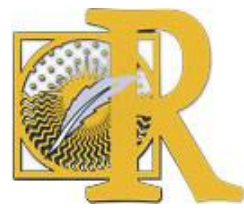

Fecha de recepción: 01-04-2019 Fecha de aceptación: 30-05-2019 


\section{KEYWORDS.}

Digital competence, ICT, higher education, teacher training.

\section{Introducción.}

Las Tecnologías de la Información y Comunicación (TIC) son una prioridad educativa que debemos considerar, especialmente en la formación inicial de los maestros (Cabero y Barroso, 2015; De Pablos, 2015; Sevillano y Vázquez, 2015). Teniendo en cuenta que el potencial de muchos recursos TIC, como las redes sociales está descubriéndose todavía, proporcionando nuevas dimensiones a la formación de alumnos y docentes (Borromeo, 2016).

Así, lógicamente la competencia digital en la formación inicial de los futuros maestros es un tema clave en esta sociedad altamente tecnificada (Roblizo y Cózar, 2015; Grande, Cañón y Cantón, 2016; Gutiérrez, Cabero y Estrada, 2017; Rodríguez-García, Raso y Ruiz-Palmero, 2019). Es una competencia que requiere habilidades tanto cognitivas, como tecnológicas y éticas (Calvani et al., 2009) además de conllevar el uso seguro y crítico de las tecnologías (Comisión Europea, 2006). La competencia digital se perfila necesaria para la participación en la sociedad ya que su uso va a permitir alcanzar los objetivos en cuanto a trabajo, empleabilidad, aprendizaje, inclusión, participación en la sociedad, etc. (Ferrari, 2013; INTEF, 2014; 2017).

Además, las redes sociales en educación han ido cobrando una importancia creciente (Abella y Delgado, 2015), demandando reacciones por parte del entorno universitario (Sevillano y Vázquez, 2015; López-Gil, Bernal-Bravo, 2019). Al mismo tiempo no debemos ignorar los riesgos que pueden tener las redes (Garaigordobil y Martínez-Valderrey, 2014), aumentando los efectos perjudiciales de conductas negativas debido a su velocidad, persistencia en el tiempo y alcance.

A este respecto, varias investigaciones sobre la competencia digital de los futuros maestros, tanto nacionales (Espuny, González y Gisbert, 2010; Roig y Pascual, 2012; Pérez y Vílchez, 2012; Cabezas, Casillas y Pinto, 2014; Gutiérrez-Castillo, Cabero-Almenara, y Estrada-Vidal, 2017; Cantón, Cañón y Grande, 2017; Moreno, Gabarda y Rodríguez, 2018; López-Gil y Bernal-Bravo, 2019; Rodríguez-García et al., 2019; López-Gil y Bernal-Bravo, 2019) como internacionales (Burnett, 2011; Duncan-Howell, 2012; Chan, Churchill y Chiu, 2017; Chen, Zhou, Tan y Wong, 2013; Rokebes y Krumsvik, 2014) señalan las dificultades que los futuros maestros tienen para emplear las TIC en el proceso educativo. Sin embargo, las referencias a la seguridad y a la privacidad son escasas.

En este sentido, Pérez y Vílchez (2012), encuentran que los varones juegan más online y las mujeres usan más las redes sociales; pero ni unos ni otros son realmente conscientes del impacto de las TIC en la sociedad. Por su parte, Cabezas, Casillas y Pinto (2014) observan que la mayoría de los encuestados afirman utilizar las redes sociales, así como servicios para publicar y compartir fotografías y videos. El uso que hacen de las TIC parece más enfocado al ocio y a las relaciones personales que al ámbito educativo o profesional. En esta línea, Duncan-Howell (2012), en Australia, afirma que más de un 75\% de los estudiantes australianos de Grado en Educación se perciben competentes con las TIC, sobre todo en las áreas relacionadas con el ocio y su vida personal. Usan la tecnología para estar

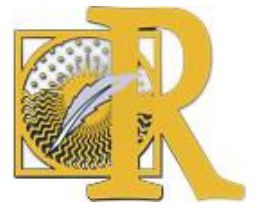


constantemente conectados a sus seres queridos y ampliar sus relaciones sociales, a través de nuevos canales de comunicación (Facebook, chat online, e-mail, etc.).

Ante la complejidad de la competencia digital han surgido varios modelos entre los cuáles tomaremos como referente el modelo DIGCOMP, dentro del contexto del Espacio Europeo de Educación Superior (EEES) (Ferrari, 2013; INTEF, 2014; 2017).

Este modelo, adaptado en nuestro país (INTEF, 2014; INTEF 2017), divide la competencia digital en 21 subcompetencias, organizadas a su vez en cinco áreas o dimensiones (Ferrari, 2013; INTEF, 2014; 2017), muchas de ellas relacionadas e interconectadas entre sí: Información, Comunicación, Creación de contenidos, Seguridad y Resolución de Problemas. En este estudio nos centraremos en la seguridad, entendida como la capacidad para proteger la información, los datos personales y la identidad digital; a las medidas de seguridad y al uso responsable y seguro y en concreto en dos de sus cuatro subdimensiones: protección de dispositivos y protección de datos personales e identidad digital.

\begin{tabular}{llr}
\hline Subdimensión de Seguridad (SEG) & En esta investigación \\
\hline 4.1 Protección de dispositivos & $\begin{array}{l}\text { Protección de dispositivos } \\
\text { (SEG-A) }\end{array}$ & \\
\hline $\begin{array}{l}\text { 4.2 Protección de datos personales e identidad } \\
\text { digital }\end{array}$ & $\begin{array}{l}\text { Protección de datos } \\
\text { personales e identidad digital } \\
\text { (SEG-B) }\end{array}$ \\
\hline 4.3 Protección de la salud & $\begin{array}{l}\text { No contemplado en esta } \\
\text { investigación }\end{array}$ & \\
\hline 4.4 Protección del entorno & $\begin{array}{l}\text { No contemplado en esta } \\
\text { investigación }\end{array}$ &
\end{tabular}

\section{Tabla 1. Subdimensiones de la Dimensión Seguridad (SEG)}

Respecto a esta Dimensión, investigaciones recientes en nuestro país, como la realizada en la Universidad de Valencia por Moreno, Gabarda y Rodríguez (2018), muestra que los alumnos que cursan estudios universitarios presentan carencias en dos aspectos, fundamentalmente: innovación y seguridad. Dado que esta investigación trata de la autopercepción, es importante señalar que, en caso de existir una diferencia relevante entre esta y la conducta real, podemos estar en una situación preocupante, ya que la autopercepción es una cuestión vital dentro de la prevención de conductas de riesgo (García del Castillo, 2012).

Esto no debe llamar necesariamente al desánimo ya que muchos jóvenes (más del 50\%) son muy prudentes o prudentes y muy competentes en relación a los riesgos presentes en los entornos online, como señalan Ramos-Soler, López-Sánchez y Torrecillas-Lacave (2018), si bien el concepto de nativos digitales (Prensky, 2001; 2011) ha provocado un optimismo injustificado en las competencias digitales de los jóvenes, que en algunas cuestiones parecen carecer de profundidad y capacidad crítica (López-Gil y Bernal-Bravo, 2019).

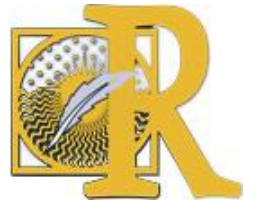




\section{Material y métodos.}

La investigación se ha articulado en torno al objetivo de analizar y conocer la autopercepción que el alumnado del Grado de Maestro de Educación Primaria de la Universidad de León tiene de la dimensión de Seguridad dentro de la competencia digital. Así como relacionarlo con otros factores, como el sexo o la familiaridad con la tecnología.

Se ha optado por la metodología no experimental de tipo descriptivo-interpretativo y expostfacto (Sevillano y Vázquez, 2015). Para obtener la muestra se ha partido de un universopoblación conformado por todo el alumnado del primer curso del Grado de Maestro de Educación Primaria de una única Facultad durante los cursos 11/12, 12/13, 13/14 y 14/15, con un total de alumnos de 492. La muestra estuvo conformada por 329 alumnos. De esta manera el estudio ofrece un nivel de confianza del $99 \%$ y un porcentaje de error del $4.09 \%$.

\section{Composición de la muestra por Curso / Promoción}

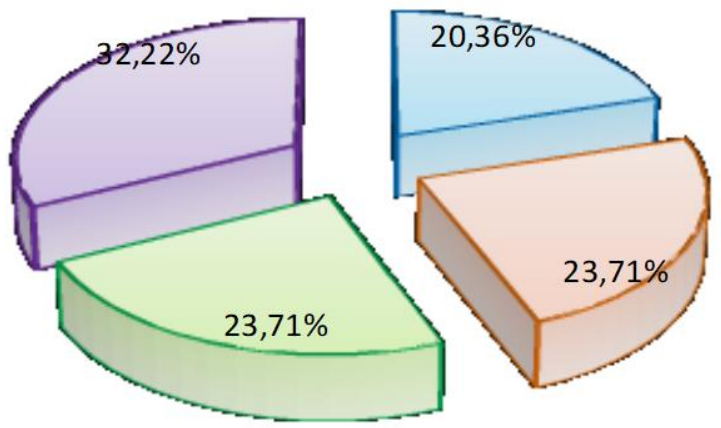

$\square$ Curso $11 / 12$

$\square$ Curso $12 / 13$

$\square$ Curso $13 / 14$

$\square$ Curso $14 / 15$

Figura 1. Composición de la muestra

Dada la amplitud de la muestra se ha optado por utilizar un único instrumento, el cuestionario, para recoger la información sobre las percepciones que tienen los futuros maestros, y que hemos denominado COTAEDU, tomando como referencia el Cuestionario COTASEBA (Cabero y Llorente, 2006). Una vez elaborado, se realizó una validación de constructo con cinco expertos y se realizó la medición de fiabilidad (Alfa de Cronbach y las Dos mitades de Guttman), obteniéndose valores superiores a 0,8 . De dicho cuestionario se seleccionaron cinco ítems específicamente relacionados con la seguridad, de los cuáles uno es cualitativo y los otros cuatro son ítems en forma de escala tipo Likert con 10 posibilidades de respuesta (0-10), donde los valores $0-4$ se consideran negativos y los valores entre 5 y 10 como positivos, siguiendo la estructura de los ítems realizada en el COTASEBA. Estos ítems han quedado distribuidos en dos subdimensiones, inspirándonos en las competencias del modelo DIGCOMP (INTEF, 2017), tal y como puede verse en la tabla 1 presentada con anterioridad. Se han analizado los datos mediante análisis de varianza y estadística descriptiva, así como tablas de contingencia y chi cuadrado en la búsqueda de correlaciones.

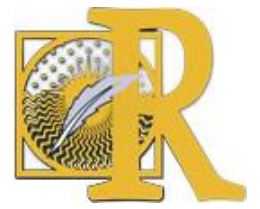

Fecha de recepción: 01-04-2019 Fecha de aceptación: 30-05-2019

Grande-de-Prado, M., Cañón-Rodríguez, R. \& García-Martín, S. Seguridad digital, ¿̇cómo se perciben los docentes en formación? 


\section{Resultados.}

\subsection{Muestra.}

De los 329 sujetos que forman la muestra, el $69.9 \%$ son mujeres y el $30.1 \%$ son hombres, que han cursado el primer año de del Grado de Maestro en Educación Primaria en el curso $2014 / 2015$ (32,2\%) en 2012/2013 y 2013/2014 (23,7\%), y en el curso 2011/2012 (20,4\%). Todos ellos alumnos de primer año de Grado en Educación Primaria.

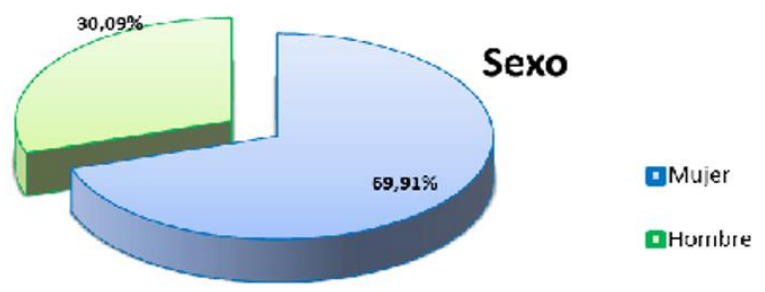

Figura 2. Porcentajes de sexo de la muestra.

\subsection{Análisis factorial.}

De las variables asociadas a la información resulta una estructura con un factor que explica el $56,750 \%$ de la varianza total.

\section{ITEMS}

FACTOR I

\begin{tabular}{|c|c|}
\hline $\begin{array}{l}\text { A) Resuelvo problemas como configurar el correo } \\
\text { electrónico, configurar antivirus, desfragmentar el disco } \\
\text { duro..., que se presenten en el ordenador o en Internet. }\end{array}$ & ,768 \\
\hline $\begin{array}{l}\text { B) Me considero competente para saber discriminar en la } \\
\text { mayoría de los casos, correo electrónico con virus, basura o } \\
\text { spam. }\end{array}$ & ,862 \\
\hline $\begin{array}{l}\text { C) Sé utilizar herramientas y recursos de la tecnología para } \\
\text { administrar y comunicar información personal y/o } \\
\text { profesional. }\end{array}$ & 820 \\
\hline $\begin{array}{l}\text { D) ¿Sabes cómo proteger tu privacidad en las redes } \\
\text { sociales? }\end{array}$ &, 515 \\
\hline FACTORES & $\begin{array}{ccc}\text { VALOR } & \% \\
\text { PROPIO } & \text { VARIANZ } \\
\text { A } & \% \text { VARIANZA TOTAL } \\
\end{array}$ \\
\hline I & 56,750 \\
\hline
\end{tabular}

Tabla 2. Relación de factores del análisis factorial de la dimensión de Seguridad

Este factor, denominado Seguridad, explica el $56,750 \%$ de la varianza, es decir la totalidad, e incluye todos los ítems de esta dimensión (A; B; C y D), relativos a la privacidad y redes sociales.

Como puede observarse (tabla 3 ) se han agrupado los diferentes ítems que se encuentran dentro de las Subdimensiones creadas partiendo del DIGCOMP (Ferrari, 2013; INTEF, 2014; 2017), referidas a la Protección de dispositivos y a la Protección de datos de identidad digital.

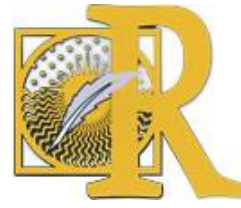




\section{INTERNATIONAL JOURNAL OF EDUCATIONAL \\ RESEARCH AND INNOVATION \\ REVISTA INTERNACIONAL DE INVESTIGACIÓN \\ EINNOVACIÓN EDUCATIVA}

Mario Grande-de-Prado, Ruth Cañón-Rodríguez \& Sheila García-Martín. Seguridad digital, ¿cómo se perciben los docentes en formación?

\begin{tabular}{cccc}
\hline $\begin{array}{c}\text { Abreviatura } \\
\text { empleada }\end{array}$ & Subdimensiones & Ítems & $\begin{array}{c}\text { Ítems por } \\
\text { Subdimensión }\end{array}$ \\
\hline SEG-A & $\begin{array}{c}\text { Protección de } \\
\text { dispositivos }\end{array}$ & $\mathrm{A} ; \mathrm{B} ; \mathrm{C}$ & 3 \\
\hline SEG-B & $\begin{array}{c}\text { Protección de datos e } \\
\text { identidad digital }\end{array}$ & $\mathrm{D}$ & 1 \\
\hline
\end{tabular}

Tabla 3. Relación de factores del análisis factorial de la dimensión de Seguridad.

\subsection{Datos descriptivos}

Respecto a los sujetos de la muestra, en su mayoría $(89,1 \%)$ consideran que Internet tiene un gran peso en su vida diaria.

Para realizar el análisis de esta dimensión hemos partido del factor Seguridad, en el que se encuentran incluidas las dos Subdimensiones que vamos a considerar (Protección de dispositivos SEG-A y Protección de datos personales SEG-B).

En estas dos Subdimensiones (SEG-A y SEG-B), en las que se engloban los ítems que hacen referencia a la Protección de dispositivos (SEG-A) y a la Protección de datos personales (SEG-B), hemos obtenido medias superiores a 5 en todos los ítems, lo cual nos lleva a señalar que el alumnado del Grado de Educación Primaria de la Universidad de León se siente como mínimo moderadamente competentes para realizar todas las habilidades de esta subdimensión.

\begin{tabular}{lcccc}
\hline Ítem & Media & Mediana & Moda & $\begin{array}{c}\text { Desv. } \\
\text { típica }\end{array}$ \\
\hline & & & & \\
A.- Problemas de configuración y mantenimiento & 5,51 & 6 & 6 & 2,394 \\
\hline & & & & \\
B.- Correos con virus, basura o spam & 5,68 & 6 & 7 & 2,495 \\
\hline & & & & \\
C.- Administrar y comunicar información & 5,56 & 5 & 5 & 2,023 \\
\hline & & & & \\
D.- Privacidad en Redes Sociales & 7,43 & 8 & 10 & 2,356 \\
\hline
\end{tabular}

Tabla 4. Medidas de tendencia central de los ítems de la Dimensión SEG.

El ítem mejor puntuado, nos indica que el alumnado participante considera que se siente bastante competente para proteger su privacidad en las redes sociales (ítem D), lo que no significa que no sea competente para resolver problemas de configuración y mantenimiento (ítem A), para saber discriminar en la mayoría de los casos, correo electrónico con virus, basura o spam (ítem B) y para utilizar herramientas y recursos de la tecnología para administrar y comunicar información personal y/o profesional (ítem C). 


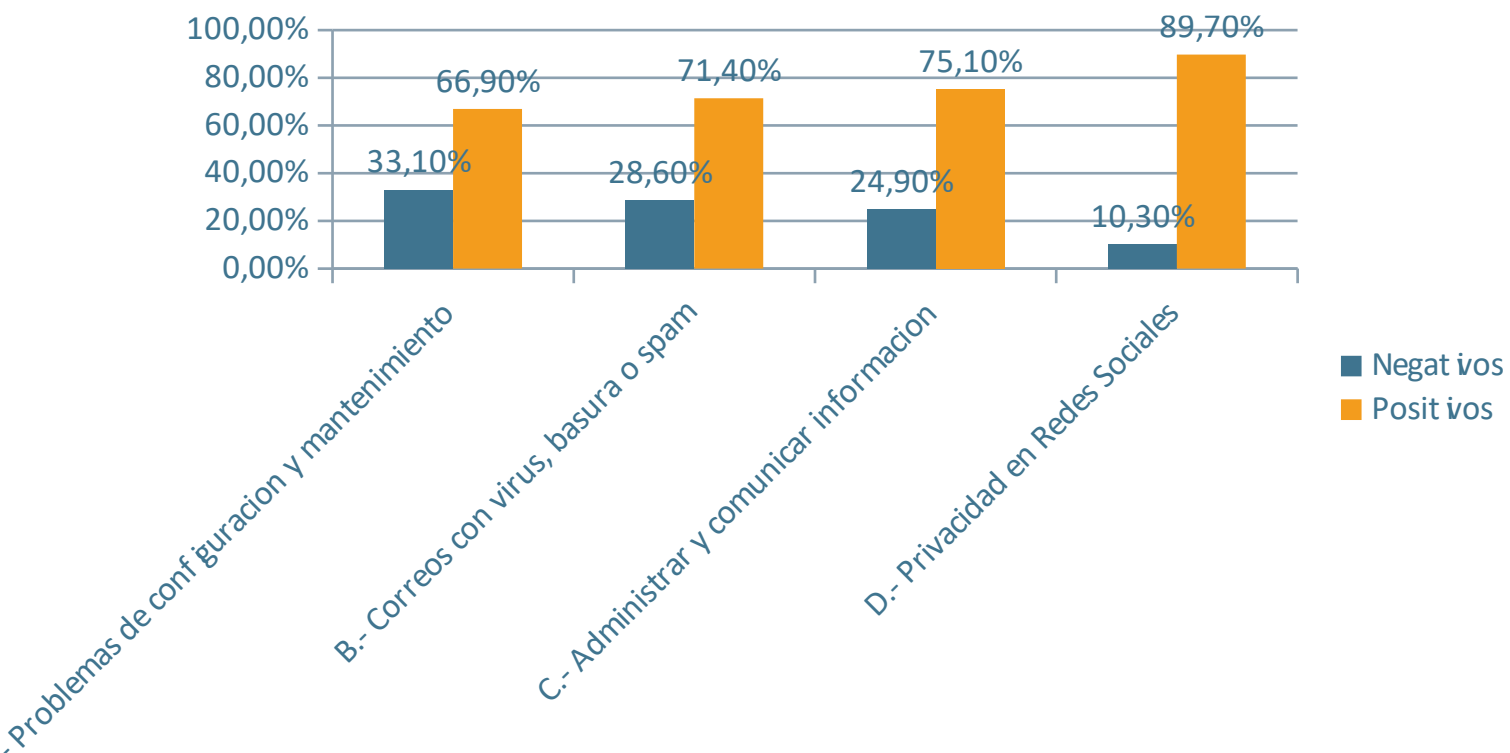

Figura 3. Respuestas negativas y positivas de los ítems cuantitativos.

De forma general, en la Figura 3, se observa un alto índice de valoraciones positivas agrupadas (de 5 a 10) en las que destaca el ítem $D(89,7 \%)$, referido a la proteger su privacidad en las redes sociales mientras que, desde la visión contraria, la capacidad para resolver problemas de configuración y mantenimiento (ítem A), es el que presenta la valoración negativa global más alta $(33,10 \%)$. Corresponde a este ítem la frecuencia negativa más alta, un $13,1 \%$ en el valor cuatro.

\begin{tabular}{ll|l}
\hline Ítem & Negativo (0-4) & Positivo (5-10) \\
\hline A.- Problemas de configuración y mantenimiento & $33,1 \%$ & $66,9 \%$ \\
\hline B.- Correos con virus, basura o spam & $28,6 \%$ & $71,4 \%$ \\
\hline C.- Administrar y comunicar información & $24,9 \%$ & $75,1 \%$ \\
\hline D.- Privacidad en Redes Sociales & $10,3 \%$ & $89,7 \%$ \\
\hline
\end{tabular}

Tabla 5. Porcentajes de respuestas positivas y negativas (ítems cuantitativos).

En base a las puntuaciones obtenidas, podemos afirmar que la mayoría del alumnado encuestado se siente competente en cuestiones relacionadas con aspectos vinculados a su seguridad, tal como se muestra en la Tabla 5, en la que todos los ítems presentan perfiles que demuestran una tendencia positiva, de entre los cuáles en el ítem $D$ destaca especialmente la frecuencia $(20,7 \%)$ del valor extremo 10.

Para terminar la descripción de esta dimensión, resulta interesante considerar la información aportada por el ítem cualitativo referido a si consideran peligroso subir fotografías a las redes sociales (ítem $\mathrm{E}$ ), obteniéndose que más de un $95 \%$ de los encuestados perciben la existencia de peligro potencial al subir fotografías a las redes sociales ("Sí" o "Depende").

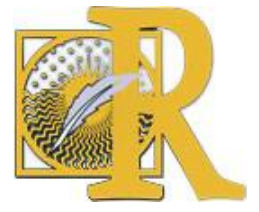

Fecha de recepción: 01-04-2019 Fecha de aceptación: 30-05-2019 


\begin{tabular}{lcc}
\hline Respuesta & Frecuencia & Porcentaje \\
\hline No & 7 & 2,1 \\
\hline Depende & 165 & 50,2 \\
\hline $\mathrm{Si}$ & 152 & 46,2 \\
\hline No lo sé & 5 & 1,5 \\
\hline Total & 329 & 100,0 \\
\hline
\end{tabular}

Tabla 6. Percepción de peligrosidad de fotos en redes sociales (ítem E - Cualitativo-).

\subsection{Diferencias por sexos.}

El cuestionario, tal como se ha comentado anteriormente, posee ítems cualitativos y cuantitativos, por ello es necesario utilizar diferentes pruebas en base al tipo de variable. En el caso de los ítems cualitativos hemos realizado un análisis mediante tablas de contingencia, tomando como referencia los coeficientes de correlación para determinar la significatividad de la relación entre las variables. En cambio, para los ítems cuantitativos tras realizar la prueba de Kolmogorov-Smirnov, una medida de "bondad de ajuste", que nos permite saber si la muestra presenta una distribución normal, se observa que todos los ítems de escala rechazan la hipótesis de la normalidad de la distribución con la prueba Kolmogorov-Smirnov (ver tabla 7).

Esto nos indica la necesidad de usar pruebas no paramétricas. Aun así, la falta de normalidad no es un problema severo para el ANOVA, que es robusta ante la falta de normalidad.

\section{Nombre abreviado del ítem}

\section{Normalidad} (Kolmogorov-Smirnov)

\begin{tabular}{ll}
\hline A.- Problemas de configuración y mantenimiento & 0,000 \\
\hline B.- Correos con virus, basura o spam & 0,000 \\
\hline C.- Administrar y comunicar información & 0,000 \\
\hline D.- Privacidad en Redes Sociales & 0,000
\end{tabular}

Tabla 7. Análisis de la normalidad de la distribución con la prueba Kolmogorov-Smirnov.

También se ha realizado una búsqueda de diferencias con pruebas no paramétricas, como la prueba $U$ de Mann Whitney. Y, para profundizar en esos resultados se ha utilizado el ANOVA, para conseguir una mayor riqueza de datos, empleando para ello la prueba de Scheffé, muy extendida y bastante conservadora (Ver tabla 8). Resaltaremos aquellos ítems en los que la significativad en el ANOVA y en las pruebas no paramétricas sea inferior a 0,005 ; y consideraremos menos robustos, estadísticamente hablando, aquellos que no cumplan las dos condiciones. De esta manera, nos hemos centrado en aquellos resultados que satisfacen ambas pruebas estadísticas. 


\begin{tabular}{lcc}
\hline Ítem & U de Mann Whitney & ANOVA \\
\hline A.- Problemas de configuración y mantenimiento & 0,010 & 0,000 \\
\hline B.- Correos con virus, basura o spam & 0,000 & 0,000 \\
\hline C.- Administrar y comunicar información & 0,250 & 0,019 \\
\hline
\end{tabular}

Tabla 8. Items significativos relacionados con el Sexo

En relación al sexo, como puede observarse en la Tabla 9, en general los hombres puntúan más alto que las mujeres.

\begin{tabular}{|c|c|c|c|c|c|}
\hline ITEM & & Media & $\begin{array}{l}\text { Desviación } \\
\text { típica }\end{array}$ & $\begin{array}{c}\text { Diferencia } \\
\text { entre } \\
\text { medias } \\
\text { (Hombre / } \\
\text { Mujer) }\end{array}$ & $\begin{array}{c}\text { Diferencia } \\
\text { entre Desv. } \\
\text { Típ. } \\
\text { (Hombre / } \\
\text { Mujer) }\end{array}$ \\
\hline \multirow{3}{*}{$\begin{array}{l}\text { A) Resuelvo problemas como configurar el } \\
\text { correo electrónico, configurar antivirus, } \\
\text { desfragmentar el disco duro..., que se } \\
\text { presenten en el ordenador o en Internet. }\end{array}$} & Mujer & 5,21 & 2,388 & \multirow{3}{*}{1,00} & \multirow{3}{*}{0,12} \\
\hline & $\begin{array}{c}\text { Hombr } \\
\mathrm{e}\end{array}$ & 6,21 & 2,269 & & \\
\hline & Total & 5,51 & 2,394 & & \\
\hline \multirow{3}{*}{$\begin{array}{l}\text { B) Me considero competente para saber } \\
\text { discriminar en la mayoría de los casos, } \\
\text { correo electrónico con virus, basura o } \\
\text { spam. }\end{array}$} & Mujer & 5,34 & 2,530 & \multirow{3}{*}{1,14} & \multirow{3}{*}{0,31} \\
\hline & $\begin{array}{c}\text { Hombr } \\
\mathrm{e}\end{array}$ & 6,48 & 2,224 & & \\
\hline & Total & 5,68 & 2,495 & & \\
\hline \multirow{3}{*}{$\begin{array}{l}\text { C) Sé utilizar herramientas y recursos de la } \\
\text { tecnología para administrar y comunicar } \\
\text { información personal y/o profesional. }\end{array}$} & Mujer & 5,39 & 2,025 & \multirow{3}{*}{0,57} & \multirow{3}{*}{0,05} \\
\hline & $\begin{array}{c}\text { Hombr } \\
\mathrm{e}\end{array}$ & 5,96 & 1,974 & & \\
\hline & Total & 5,56 & 2,023 & & \\
\hline
\end{tabular}

Tabla 9. Comparación de medias por sexos.

\subsection{Diferencias vinculadas al acceso a Internet en casa.}

La posible correlación entre el acceso a internet en casa y otras variables cualitativas se ha analizado mediante tablas de contingencia y Chi Cuadrado, encontrándose relación entre el acceso a internet y percepción de peligro al subir fotos a redes sociales (Ver Tabla 10) con una significatividad de 0,048 . 


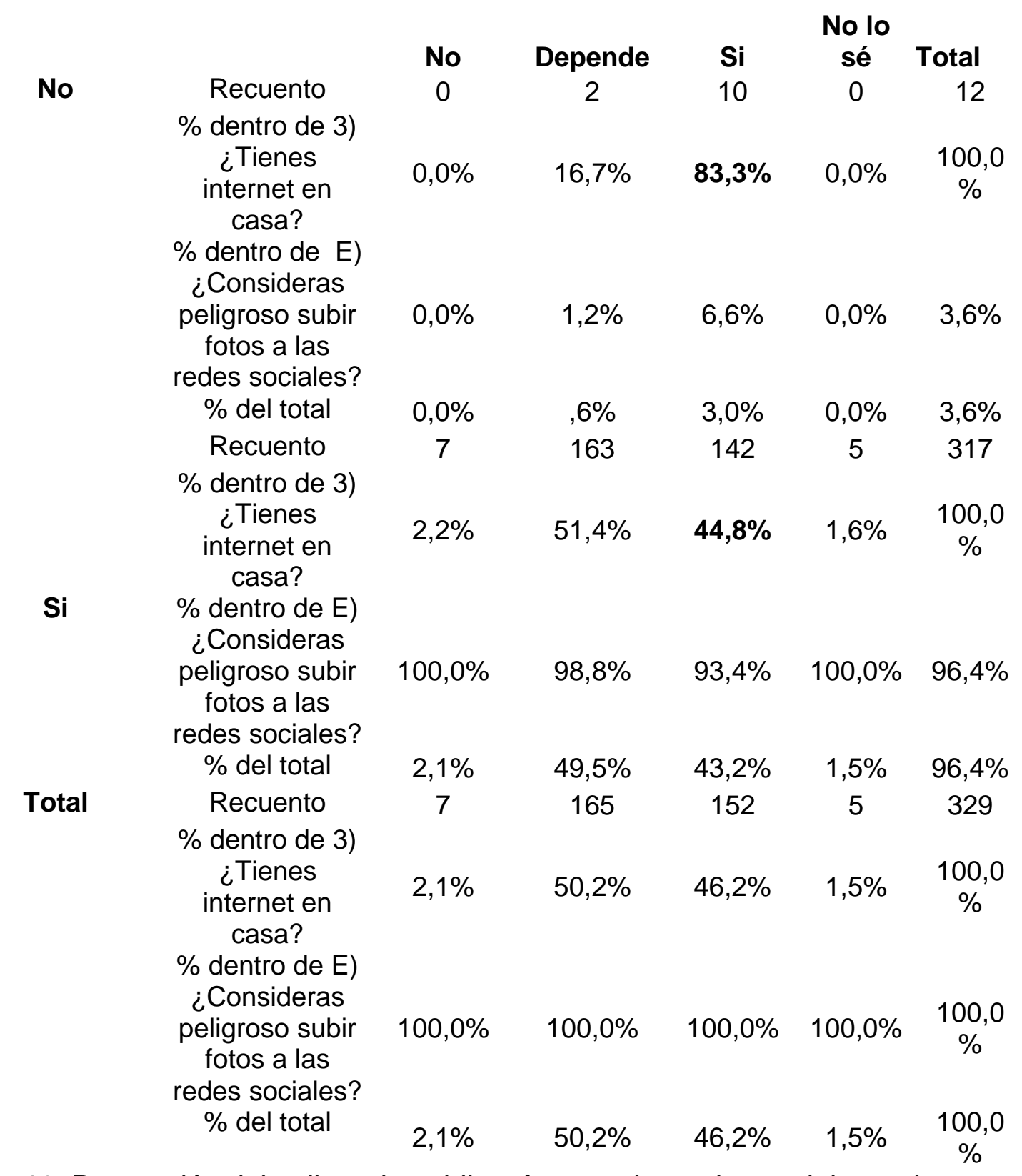

Tabla 10. Percepción del peligro de publicar fotos en las redes sociales y el acceso a internet.

Como se puede observar, un $83,3 \%$ de los encuestados que no tienen internet en casa muestran una mayor percepción de peligro que los que sí lo tienen, que mayoritariamente se posicionan en posturas más prudentes (51,4\% "Depende").

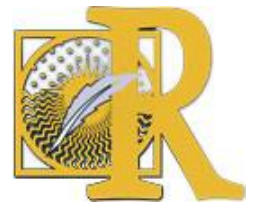




\subsection{Comparación con estudios similares.}

Tal como se ha recogido anteriormente, muchos ítems del COTAEDU están basados en el cuestionario COTASEBA (Cabero y Llorente, 2006), empleado hace años con alumnos preuniversitarios en diferentes comunidades autónomas.

A continuación, se muestra una comparativa entre los resultados de los ítems comunes con otras investigaciones.

\begin{tabular}{|c|c|c|c|c|c|}
\hline \multirow[b]{2}{*}{ Nombre abreviado } & \multicolumn{2}{|c|}{$\begin{array}{l}\text { COTAEDU (2015) } \\
\text { (Ítems } \\
\text { coincidentes) con } \\
\text { el COTASEBA }\end{array}$} & \multicolumn{3}{|c|}{$\begin{array}{c}\text { Diferencias entre medias } \\
\text { (entre las medias de otras } \\
\text { investigaciones } \\
\text { y la media COTAEDU) }\end{array}$} \\
\hline & Media & Desv. típ. & $\begin{array}{c}\text { COTASEBA } \\
\text { Original } \\
\text { (Cabero y } \\
\text { Llorente, } \\
2006 \text { ) }\end{array}$ & $\begin{array}{c}\text { E-TIC / } \\
\text { Galicia } \\
\text { (Fernández } \\
\text {, Cebreiro, } \\
\text { y } \\
\text { Fernández, } \\
2010 ; \\
2011 \text { ) }\end{array}$ & $\begin{array}{c}\text { Islas } \\
\text { Baleares } \\
\text { (Pons y } \\
\text { Salinas, } \\
\text { 2008; 2009; } \\
\text { 2012) }\end{array}$ \\
\hline $\begin{array}{l}\text { A.- Problemas de configuración y } \\
\text { mantenimiento }\end{array}$ & 5,51 & 2,394 & 0,24 & 0,41 & $-0,75$ \\
\hline $\begin{array}{c}\text { B.- Correos con virus, basura o } \\
\text { spam }\end{array}$ & 5,68 & 2,495 & 0,25 & 0,71 & $-0,75$ \\
\hline $\begin{array}{l}\text { C.- Administrar y comunicar } \\
\text { información }\end{array}$ & 5,56 & 2,023 & $-0,31$ & $-0,14$ & $-0,26$ \\
\hline
\end{tabular}

Tabla 11. Diferencias de las medias en los ítems comunes COTAEDU / COTASEBA.

Es importante recordar que existen algunas diferencias a tener en cuenta en el muestreo por la propia configuración de nuestra investigación (sexo, estudios de Bachillerato, edad...) con respecto a las demás.

\section{Discusión}

El objetivo de este estudio era conocer la percepción que tienen de sí mismos los maestros en formación sobre cuestiones de seguridad digital. En este ámbito, los fututos docentes se autoperciben como moderadamente competentes en cuestiones relativas a la gestión de correo y antivirus, al mantenimiento básico y prevención de problemas en el equipo y a la administración y comunicación de información personal y/o profesional.

En cuanto al sexo, resulta llamativo que los hombres puntúen por encima de las mujeres en los ítems relativos a la Subdimensión de Protección de Dispositivos (SEG-A) mientras que las mujeres obtienen mejores resultados (aunque no sean estadísticamente reseñables) respecto a la Protección de datos e identidad digital (SEG-B). Lo cual puede estar relacionado con los patrones diferenciales en el uso de dispositivos digitales por parte de los hombres y mujeres (García-Martín y García-Sánchez, 2017).

A pesar de ello, no parecen existir diferencias relevantes en los ítems en común con el cuestionario COTASEBA empleado en investigaciones con preuniversitarios en varias

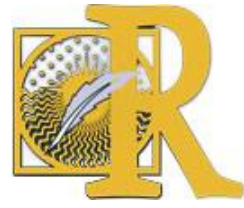

Fecha de recepción: 01-04-2019 Fecha de aceptación: 30-05-2019 
comunidades autónomas (Cabero y Llorente, 2006; Fernández, Cebreiro, y Fernández, 2011; Pons y Salinas, 2008). También es preciso destacar que aquellos alumnos con menor contacto con la tecnología parecen tener una mayor sensación de riesgo en relación al uso de las TIC.

Sobre las limitaciones de este estudio, cabe indicar que su aplicación se ha desarrollado en una única facultad y se ha aplicado un solo instrumento de recogida de datos; lo cual, evidentemente, puede lastrar las posibilidades de generalización de los resultados. Sin embargo, dada la amplitud de la muestra, puede considerarse compensada. Además, este estudio puede servir como punto de partida para otras investigaciones similares en diferentes localizaciones, así como para comparaciones entre alumnos egresados recientemente o profesores noveles ya en ejercicio, ampliando este primer contacto exploratorio con más preguntas y otras herramientas que permitan triangular los resultados; de esta manera se podría determinar si estos resultados, que reflejan la autopercepción, concuerdan (o no) con la competencia digital real.

Finalmente, destacar que la seguridad digital en los educadores es una cuestión a la que debemos prestar atención. Si realmente los futuros maestros son competentes en seguridad digital, tenemos un punto firme en el que afianzarnos. Pero si no lo son, y además no lo saben, tenemos un problema importante en el que trabajar con los docentes en formación.

\section{Referencias.}

- Abella, V.; Delgado, V. (2015) Aprender a usar twitter y usar twitter para aprender. Profesorado, 19(1). pp. 364-378. Recuperado de: http://goo.gl/gV7QaT

- Borromeo García, C.A. (2016). Redes sociales para la enseñanza de idiomas: el caso de los profesores. Píxel-Bit. Revista de Medios y Educación, 48, 41-50 http://dx.doi.org/10.12795/pixelbit.2016.i48.03

- Burnett, C. (2011). Preservice teachers' digital literacy practices: exploring contingency in identity and digital literacy in and out of educational contexts. Language and Education, 25 (5), 433 - 449. http://dx.doi.org/10.1080/09500782.2011.584347

- Cabero, J., y Barroso, J. (2013). La escuela en la sociedad de la información. La escuela 2.0. En J. Cabero Almenara, y J. Barroso Osuna, Nuevos escenarios digitales (pp. 21-36). Madrid: Pirámide.

- Cabero, J. y Barroso, J. (Coords.) (2015). Nuevos retos en tecnología educativa. Madrid: Editorial Síntesis.

- Cabero, J. y Llorente, M. C. (2006). La rosa de los vientos. Dominios tecnológicos de las TIC por los estudiantes. Sevilla: GID.

- Cabezas, M., Casillas, S. y Pinto, A.M. (2014) Percepción de los alumnos de Educación Primaria de la Universidad de Salamanca sobre su competencia digital. EDUTEC, Revista Electrónica de Tecnología Educativa, 48. Recuperado de: http://goo.gl/FD9IZU

- Calvani, A., Cartelli, A., Fini, A., \& Ranieri, M. (2009). Models and instruments for assessing digital competence at school. Journal of ELearning and Knowledge Society-English Version, 4(3).

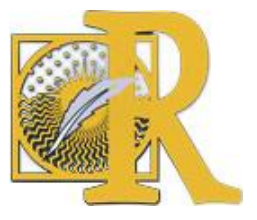

Fecha de recepción: 01-04-2019 Fecha de aceptación: 30-05-2019 Grande-de-Prado, M., Cañón-Rodríguez, R. \& García-Martín, S. Seguridad digital, ¿̇cómo se perciben los docentes en formación? 
- Cantón, I., Cañón, R. \& Grande, M. (2017). La comunicación como subdimensión de la competencia digital en futuros maestros de Educación Primaria. Pixel-Bit: Revista de medios y educación, 48, 33-47. http://dx.doi.org/doi.org/10.12795/pixelbit.2017.i50.02

- Chan, B. S., Churchill, D., \& Chiu, T. K. (2017). Digital Literacy Learning In Higher Education Through Digital Storytelling Approach. Journal of International Education Research (JIER), 13(1), 1-16.

- Chen, W., Zhou, X., Tan, A., y Wong, P. S. K. (2013). ICT experiences and competencies of pre-service teachers in the digital age. Recuperado de: https://goo.gl/BTUiBf

- Comisión Europea (2006). Competencias clave para el aprendizaje permanente. Recuperado de: http://eur-lex.europa.eu/legal-content/ES/TXT/?uri=URISERV\%3Ac11090

- De Pablos Pons, J. (Coord.) (2015). Los centros educativos ante el desafío de las tecnologías digitales. Madrid: La Muralla.

- Duncan-Howell, J. (2012). Digital mismatch: Expectations and realities of digital competency amongst pre-service education students. Australasian Journal of educational $\begin{array}{lllll}\text { Technology, } & 28 & \text { (5), } & \text { 827-840. }\end{array}$ http://www.ascilite.org.au/ajet/ajet28/duncan-howell.html

- Espuny, C. y González, J. y Gisbert, M. (2010). ¿Empezamos a navegar? La competencia digital profesional en los futuros maestros. En Alfabetización mediática y culturas digitales (p.4). Sevilla: Universidad de Sevilla.

- Fernández, C., Cebreiro, B., Fernández, C. (2011). Competencias para el aprendizaje en red de los alumnos de educación secundaria en Galicia. Pixel-Bit: Revista de medios y educación, (38), 7-21.

- Ferrari, A. (2013). DIGCOMP: A Framework for Developing and Understanding Digital Competence in Europe. Luxembourg: Publications Office of the European Union. Recuperado de: http://goo.gl//4t1d8

- Garaigordobil, M., \& Martínez-Valderrey, V. (2014), "Effect of Cyberprogram 2.0 on Reducing Victimization and Improving Social Competence in Adolescence". Psicodidáctica, 19(2), 289-305. doi: 10.1387/RevPsicodidact.102310196

- García-del-Castillo, J. A. (2012). Concepto de percepción de riesgo y su repercusión en las adicciones. Health and Addictions, 12(2), 133-151. Recuperado de: https://goo.gl/Xcvqmu

- García-Martín, J. \& García-Sánchez, J.N. (2017). Pre-service teachers' perceptions of the competence dimensions of digital literacy and of psychological and educational measures. Computers \& Education, 107, 54-67. http://dx.doi.org/10.1016/j.compedu.2016.12.010

- Grande, M., Cañón, R., \& Cantón, I. (2016). Tecnologías de la información y la comunicación: Evolución del concepto y características. International Journal of Educational Research and Innovation (IJERI), 6, 218-230.

- Gutiérrez-Castillo, J. J., Cabero-Almenara, J., \& Estrada-Vidal, L. I. (2017). Diseño y validación de un instrumento de evaluación de la competencia digital del estudiante universitario. Revista Espacios, 38 (10), 1-27.

- López-Gil, M. \& Bernal-Bravo, C. (2019). El perfil del profesorado en la Sociedad Red: reflexiones sobre las competencias digitales de los y las estudiantes en Educación de la

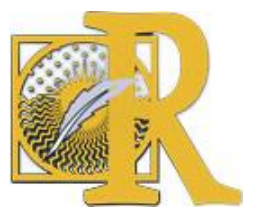

Fecha de recepción: 01-04-2019 Fecha de aceptación: 30-05-2019 Grande-de-Prado, M., Cañón-Rodríguez, R. \& García-Martín, S. Seguridad digital, ¿̇cómo se perciben los docentes en formación? 
Universidad de Cádiz. International Journal of Educational Research and Innovation (IJERI), 11, 83-100.

- INTEF (2014). Marco Común de COMPETENCIA DIGITAL DOCENTE V 2.0. Madrid: Ministerio de Educación, Cultura y Deporte. Recuperado de http://goo.gl/DmZA1t

- INTEF (2017). Marco Común de COMPETENCIA DIGITAL DOCENTE V 2.0. Madrid: Ministerio de Educación, Cultura y Deporte. Recuperado de http://educalab.es/documents/10180/12809/MarcoComunCompeDigiDoceV2.pdf

- Moreno Rodríguez, M., Gabarda Méndez, V., \& Rodríguez Martín, A. (2018). Alfabetización informacional y competencia digital en estudiantes de Magisterio. Profesorado, Revista De

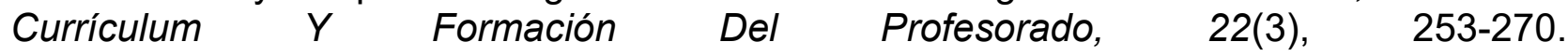
doi:10.30827/profesorado.v22i3.8001

- Pérez, F., y Vilchez, J. E. (2012). El uso de los videojuegos y redes sociales como predictores de la integración curricular de las TIC en estudiantes de Magisterio. Sphera Pública, (12), pp. 199-215. Recuperado de: http://goo.gl/filurf

- Pons, B. y Salinas, J. (2008). Competències tecnològiques dels alumnes i professors de les Illes Balears. Anuari de l'educació de les Illes Balears. Mallorca: Universitat de les Illes Balears.

- Prensky, M. (2001). Digital Natives, Digital Inmigrants. On the Horizon, 9 (5), pp. 1-6.

- Prensky, M (2011). Enseñar a Nativos Digitales. Madrid: SM.

- Ramos-Soler, I., \& López-Sánchez, C., \& Torrecillas-Lacave, T. (2018). Percepción de riesgo online en jóvenes y su efecto en el comportamiento digital. Comunicar, XXVI (56), 71-79. http://dx.doi.org/https://doi.org/10.3916/C56-2018-07

- Roblizo, M.J, y Cózar, R. (2015). Usos y competencias en TIC en los futuros maestros de educación infantil y primaria: Hacia una alfabetización tecnológica real para docentes. Pixel-Bit: Revista de medios y educación, (47), 23-39. http://dx.doi.org/10.12795/pixelbit.2015.i47.02

- Rodríguez-García, A., Raso Sánchez, F., \& Ruiz-Palmero, J. (2019). Competencia digital, educación superior y formación del profesorado: un estudio de meta-análisis en la web of science. Píxel Bit. Revista de Medios y Educación, 0(54), 65-82. http://dx.doi.org/10.12795/pixelbit.2019.i54.04

- Rodríguez-García, A.M., Martínez y Raso, F. (2017). La formación del profesorado en competencia digital: clave para la educación del siglo XXI. Revista Internacional de Didáctica y Organización Educativa, 3(2), 46-65.

- Roig, R. y Pascual, A. M. (2012). Las competencias digitales de los futuros docentes. Un análisis con estudiantes de Magisterio de Educación Infantil de la Universidad de Alicante. @tic. Revista d'innovació educativa, 9, 53-60 Recuperado de: http://rua.ua.es/dspace/bitstream/10045/25885/1/1473.pdf.

- Rokenes, F., y Krumsvik, R. J. (2014). Development of Student Teachers' Digital Competence in Teacher Education - A Literature Review. Nordic Journal of Digital Literacy, 4, 250-280. Recuperado de: http://goo.gl/llqOkR

- Sevillano, M. L. y Vázquez Cano, E. (2015). Modelos de investigación en contextos ubicuos y móviles en educación superior. Madrid: McGraw-Hill y UNED.

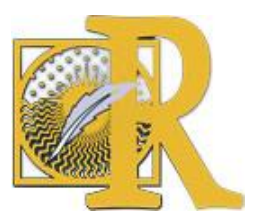

Fecha de recepción: 01-04-2019 Fecha de aceptación: 30-05-2019 